\title{
Anatomo-proteomic characterization of human basal ganglia: focus on striatum and globus pallidus
}

\author{
Joaquín Fernández-Irigoyen ${ }^{1}$, María Victoria Zelaya², Teresa Tuñon ${ }^{3}$ and Enrique Santamaría ${ }^{*}$
}

\begin{abstract}
Background: The basal ganglia (BG) are a complex network of subcortical nuclei involved in the coordination and integration of the motor activity. Although these independent anatomical structures are functionally related, the proteome present in each isolated nucleus remains largely unexplored. In order to analyse the BG proteome in a large-scale format, we used a multi-dimensional fractionation approach which combines isolation of anatomically-defined nuclei, and protein/peptide chromatographic fractionation strategies coupled to mass spectrometry.
\end{abstract}

Results: Using this workflow, we have obtained a proteomic expression profile across striatum and globus pallidus structures among which 1681 proteins were located in caudate nucleus (CN), 1329 in putamen, 1419 in medial globus pallidus (GPi), and 1480 in lateral globus pallidus (GPe), establishing a BG reference proteome to a depth of 2979 unique proteins. Protein interactome mapping highlighted significant clustering of common proteins in striatal and pallidal structures, contributing to oxidative phosphorylation, protein degradation and neurotrophin signalling pathways. In silico analyses emphasized specific pathways represented in striatal and pallidal structures highlighting 5-hydroxytryptamine degradation, synaptic vesicle trafficking, and dopamine, metabotropic glutamate and muscarinic acetylcholine receptor pathways. Additional bioinformatic analyses also revealed that: i) nearly $4 \%$ of identified proteins have been previously associated to neurodegenerative syndromes, ii) $11 \%$ of protein set tends to localize to synaptic terminal, and iii) 20\% of identified proteins were also localized in cerebrospinal fluid (CSF).

Conclusions: Overall, the anatomo-proteomic profiling of BG complements the anatomical atlas of the human brain transcriptome, increasing our knowledge about the molecular basis of the BG and the etiology of the movement disorders.

Keywords: Basal ganglia, Striatum, Globus pallidus, Proteomics, Mass spectrometry, Bioinformatics

\section{Background}

The basal ganglia (BG) and related nuclei consist of a variety of subcortical cell groups involved primarily in motor control, together with several roles in emotions and executive functions and behavior [1,2]. The term BG refers to nuclei embedded deep in the brain hemispheres (striatum or CN-putamen) and globus pallidus (GP), whereas related nuclei consist of structures located in the diencephalon (subthalamic nucleus), and mesencephalon (substantia nigra) [3]. The $\mathrm{CN}$, the putamen,

\footnotetext{
* Correspondence: esantamma@navarra.es

'Clinical Neuroproteomics Group, Proteomics Unit, Proteored-ISCIII,

Navarrabiomed, Fundación Miguel Servet, Irunlarrea Street, 31008 Pamplona, Spain

Full list of author information is available at the end of the article
}

and the accumbens nucleus are all considered input nuclei, structures that receive incoming information from different sources such as cortex, thalamus, and substantia nigra (SN). The medial globus pallidus (GPi), and the SN pars reticulata $(\mathrm{SNr})$ structures are the output nuclei, sending BG information to the thalamus. Finally, intrinsic nuclei such as the lateral globus pallidus (GPe), the subthalamic nucleus (STN) and the substantia nigra pars compacta (SNc) are located between the input and output nuclei [4].

Dopamine finely tunes striatal input as well as neuronal striatal activity, and modulates GPe, GPi, and STN activity. In the motor circuit, the striatum receives glutamatergic afferents from the cortex and thalamus and dopaminergic innervation from the SN. The putamen projects inhibitory GABAergic axons to both pallidal 
segments GPe and GPi which also receives glutamatergic fibers from the STN. The thalamus projects to the striatum and STN and the dopaminergic fibers also reach the GP, STN, thalamus, and brainstem [5].

Major cell types of BG neurons are highly specialized and are classified based on morphological, physiological and neurochemical properties. The striatum is the largest subcortical brain structure in the mammalian brain, containing projection neurons (medium-sized spiny neurons) and interneurons. Both types of cells are inhibitory neurons that use $\gamma$-aminobutyric acid (GABA) as the neurotransmitter [6]. Projection neurons could be also divided according to their projection targets, into those innervating the GPe nucleus and those projecting to the GPi and SNr. Both types of projection neurons differ also in the dopamine receptor subtype expressed and in the ability to inhibit/activate the adenyl-cyclase pathway [7]. At least, four types of GABAergic interneurons have been characterized according to their electrophysiological and neurochemical properties [8]. Both GP nuclei are composed of sparsely distributed GABAergic neurons with large somas, characterized by an enhaced expression of the calcium-binding protein parvalbumin [7].

In the last decade, different -omics strategies have been used to understand the molecular organization and complexity of different regions of the brain [9-12]. Specifically, quantitative proteomics based on a combination of 2-DE or ${ }^{18} \mathrm{O}$ labelling with MS has been used to describe protein profiles of striatum in rat and macaque models of L-DOPA-induced dyskinesia [13-16] and also in several models of Huntington's and Parkinson's diseases [16-25]. In particular, proteomic technologies have been also applied in the analysis of the substantia nigra derived from parkinsonian subjects [26-28]. On the other hand, MS-based qualitative proteomics has been employed to profile the murine striatum proteome and secretome $[29,30]$. However, despite these efforts to identify and catalogue part of the murine proteins present in BG, only a very limited number of human proteins have been characterized in these independent and functionally related substructures that compose the BG.

Here we used anatomical, protein, and peptide fractionation strategies coupled to nanoLC-MS/MS to perform a shotgun proteome-wide analysis of the human globus pallidus (GPe and GPi), CN, and putamen proteomes in depth, and present a reference proteome map of the human BG. We report the identification of 2979 protein species in basal nuclei derived from 6 healthy patients. Using integrated in-silico studies, we provide an extensive overview of molecular functions based on gene ontology term enrichment, pathways studies, and interactome network analysis. This protein compilation present in human BG paves the way toward the complete molecular characterization of subcortical structures, and may be useful to understand the molecular basis of neurodegenerative movement disorders.

\section{Results}

\section{Large-scale identification of human basal ganglia} proteomes by mass spectrometry

In the present study, we have used autopsy specimens of the right BG structures from six healthy human brains with the final goal to obtain a profound insight into the protein content and protein function of the nuclei that compose the BG. To reduce protein complexity, we used an integrated experimental workflow combining anatomical fractionation, protein IEF, and chromatographic-based methods coupled to mass spectrometry (Figure 1). For each basal nucleus, proteins were separated by IEF and the gel was sliced in 25 portions followed by in-gel trypsin digestion. The second approach involved in- solution digestion followed by off-line RP-LC at basic $\mathrm{pH}$ to separate the peptide mixture in 20 fractions. Replicate mass spectrometry measurements were performed in all peptide fractions for each basal nucleus. MS/MS data from each substructure were processed to identify peptides that gave rise to observed spectra, and proteins were inferred based on identified peptides. The number of non-redundant proteins identified with at least two unique peptides ranged from 1681 proteins for CN, 1329 for putamen, 1419 for GPi, and 1480 for GPe generating a BG reference proteome map of 2979 unique protein species, identified with a FDR lower than 1\%. Complete lists of identifications and their corresponding scores are presented in Additional file 1: Table S1, Additional file 2: Table S2, Additional file 3: Table S3, Additional file 4: Table S4 and in ProteomeXchange repository (http://proteomecentral.proteomexchange.org). As shown in Figure 2A, 30\% of the dataset (916 proteins) was exclusively detected in striatal structures (CN and putamen) while 26\% (776 proteins) was identified only in pallidal nuclei (GPe and GPi). On the other hand, 532 proteins (18\% of the protein set) overlapped between the four regions. According to Genetic Association Database [31], 100 striatal and 88 pallidal proteins have been previously linked to neurodegenerative syndromes such as schizophrenia, Parkinson's disease, Alzheimer's disease, and amyotrophic lateral sclerosis (Figure 2B and Additional file 5: Table S5). The integrated BG proteome dataset was also compared with previously published lists of human CSF proteome descriptions $[32,33]$. Interestingly, 599 proteins (20\% of the protein set) were found to exist in both the BG and CSF proteomes (Figure 2C). A subset of these proteins is known to be involved in a plethora of central nervous system functions (Additional file 6: Table S6) and some of them are implicated in the development of neurological diseases such as Alzheimer's, Parkinson's, and Huntington's diseases (Additional file 6: Table S6). 


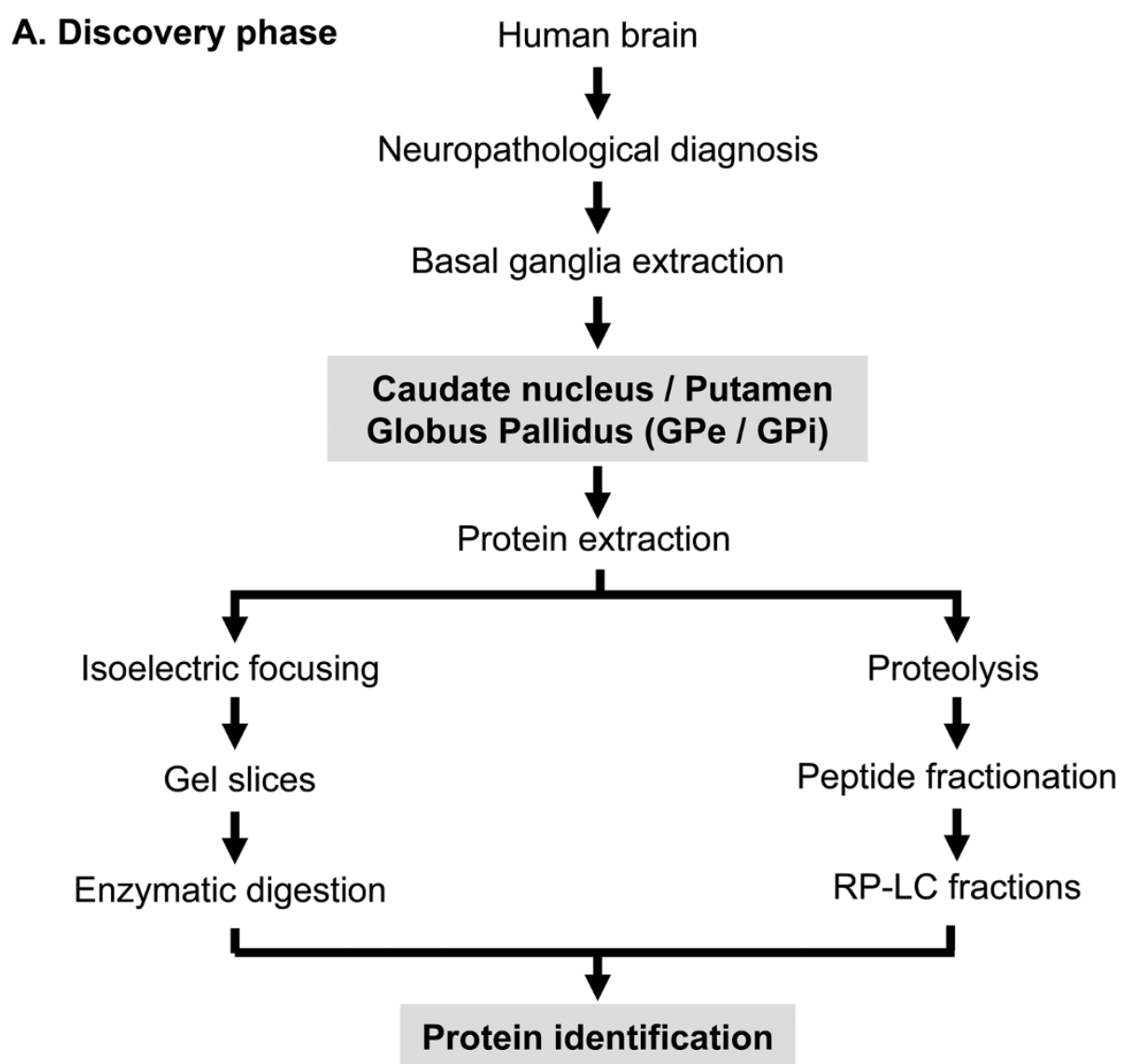

\section{B. Bioinformatic phase}

\section{Protein list compilation \\ $\downarrow$ \\ Functional information

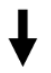

Gene ontologies / Pathways analysis / protein networks

Figure 1 An overview of the workflow used for identification of the BG proteomes.

Protein interactome map for common proteins detected in striatum and globus pallidus

To enhance the analytical outcome of proteomic experiments, we have performed a proteome-scale interaction network merging the 532 common proteins detected in GPe, GPi, CN, and putamen using the STRING software [34]. This database includes interactions from published literature describing experimentally studied interactions, as well as those from genome analysis using several well-established methods based on domain fusion, phylogenetic profiling and gene neighbourhood concepts. Accordingly, a confidence score for every protein-protein association was assigned to the network. A higher score was assigned when an association is supported by several types of evidence. To minimize false positives as well as false negatives, all interactions tagged as "low-confidence" $(<0.4)$ in STRING database have been eliminated from this study. Thus, the final network is composed by 335 nodes (proteins) and 941 edges (interactions) (Figure 3, Additional file 7: Figure S3 and Additional file 8: Table S7), establishing the first comprehensive interactomics map for the BG proteome. The 


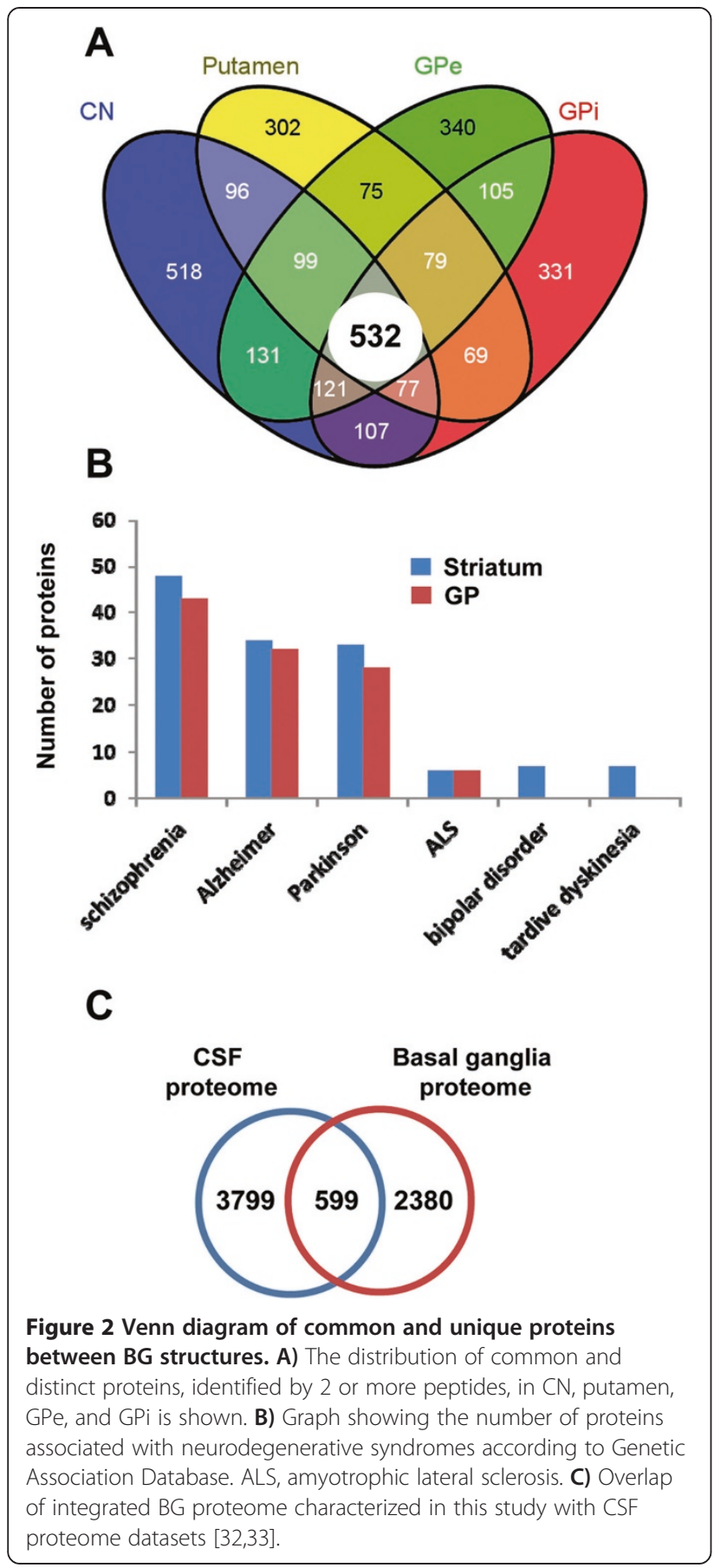

topological analysis of this network demonstrated a central interplay with highly connected interactions and several sparsely connected sub-networks (Figure 3). The main central subset is composed by 27 nodes and is referred as the oxidative phosphorylation network (Figure 3). Other overlapping sub-networks are composed by interconnected nodes linked to GTP binding and neurotrophin signalling pathway and also by nodes involved in protein degradation (Figure 3).
Contribution to the repertoire of human brain proteome Protein identification data from the current study was compared with previous proteomic descriptions derived from large-scale proteomic studies of intimately related structures from human limbic system such as amygdala [35], hippocampus [36], olfactory bulb [37], pituitary gland [38], thalamus [39], and sustantia nigra [26,28,40-42] (Figure 4). On the other hand, combining the information stored in three repositories containing the largest number of synapse specific proteins (G2Cdb, Synaptome DB, and SynsysNet) [43-45], we have constructed an integrative synaptic proteome database containing 2705 synaptic protein-coding genes (Additional file 9: Table S8). Then, we have compared our protein compilation lists with the synaptic proteome database, detecting expression of 288 and 268 synaptic proteins in striatal and pallidal structures respectively (Figure 4 and Additional file 9: Table S8). In total, 346 proteins identified in BG (11\% of the dataset) tend to localize to synaptic terminal.

\section{Functional metrics of human BG proteomes. Gene ontology analysis}

To extract biological knowledge, the striatal and pallidal proteome datasets were functionally categorized based on Gene Ontology (GO) annotation code using DAVID software [46]. From striatal and pallidal datasets, 1393 and 1308 identifiers were considered for further analysis. With respect to the biological process and molecular function categories, an enrichment analysis has been performed against Homo Sapiens background using functional annotation clustering provided in DAVID tool. Respects to biological process ontology, 24 clusters are significantly enriched in BG nuclei respect to human genome (Additional file 10: Table S9). Some of the most significantly enriched biological processes included longterm strengthening of neuromuscular junction, aerobic respiration, regulation of ubiquitin-protein ligase activity, and glucose and ATP catabolism. Representative biological process categories from each cluster in striatal and pallidal structures are shown in Additional file 7: Figure S4.

Respects to molecular function ontology, 10 clusters are significantly enriched in the BG proteome dataset (Additional file 11: Table S10). Intramolecular oxidoreductase, aminoacyl-tRNA ligase, hydrogen ion transmembrane transporter, and ATPase activities, were the most significantly enriched molecular functions in our dataset. Representative molecular function categories from each cluster in striatum and globus pallidus are represented in Additional file 7: Figure S5. Respect to cellular component ontology, a significant proportion of striatal and pallidal proteins consisted of cytosolic, mitochondrial, cytoskeletal proteins together with plasma 


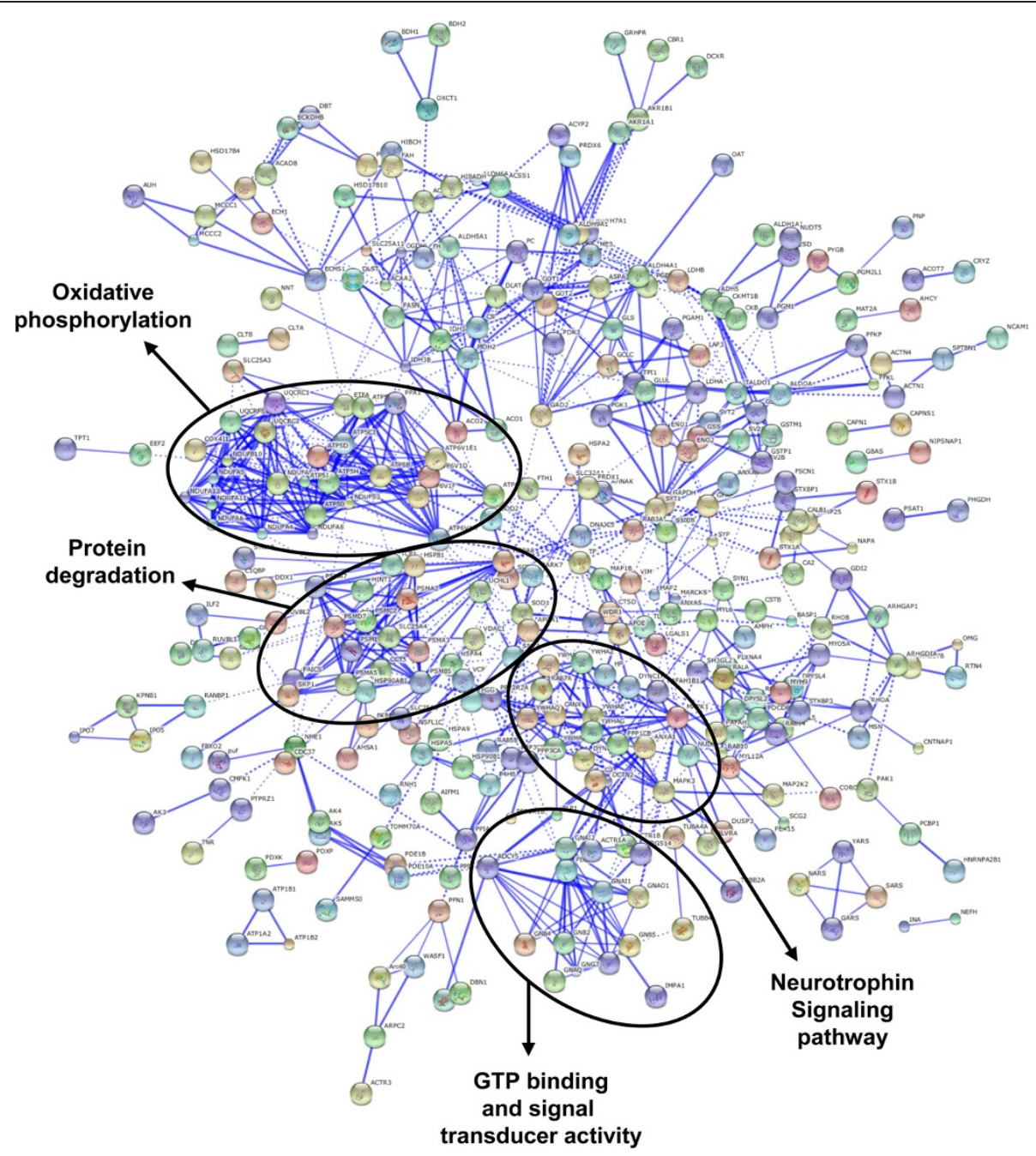

Figure 3 Protein interactome network for shared proteome between pallidal and striatal structures. Using the STRING software, proteins are represented with nodes and the interactions with continuous lines to represent direct interactions (physical), while indirect ones (functional) are presented by interrupted lines. Stronger associations are represented by thicker lines.

membrane and vesicle proteins (Additional file 7: Figure S6A and Additional file 11: Table S10). Additionally, a neuron-specific cell component analysis was also performed, detecting proteins associated to neuron projection, synapse, axon, and dendrites between others (Additional file 7: Figure S6B and Additional file 11: Table S10).

\section{Functional metrics of human BG proteomes. Pathways analysis}

A complementary analysis of biological processes was performed with a search of KEGG pathways [47], that are over-represented in human BG nuclei. The 35 pathways represented with a high statistical significance (fold enrichment $>1.5$; EASE p-value $<0.01$ ) are shown in Additional file 12: Table S11. Four of these pathways are clearly related to neurological disorders such as
Parkinson's, Alzheimer's, Huntington's, and Prion diseases. Among the KEGG pathways, oxidative phosphorylation, proteasome, and neurotrophin signalling pathway, are of particular interest because they partially reinforce the BG interactome map. Strong representation of carbohydrate, lipid, and amino acid metabolism, together with the regulation of neurological system process such as lon-term potentiation/depression and endocytosis, parallels with previous observations that GO Terms "glucose metabolism/catabolism", aminoacyltRNA ligase activity", "Fatty acid beta oxidation", "regulation of synaptic transmission" and "neurotransmitter transport" are highly enriched in basal nuclei. In order to gain a more detailed description of the molecular mechanisms represented in striatum and globus pallidus, subsequent analyses were performed to explore the striatal and pallidal proteome distributions across specific 

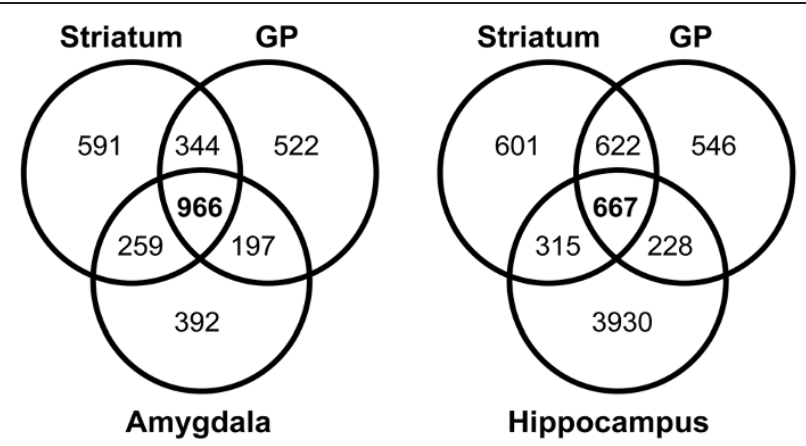

Hippocampus

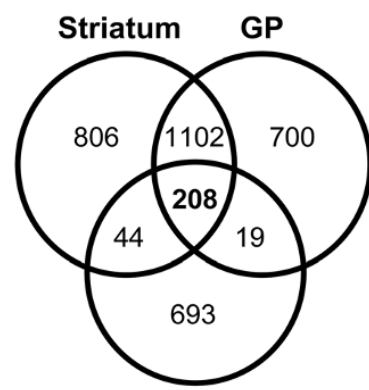

Pituitary

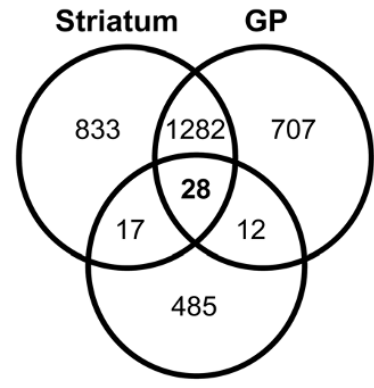

Thalamus

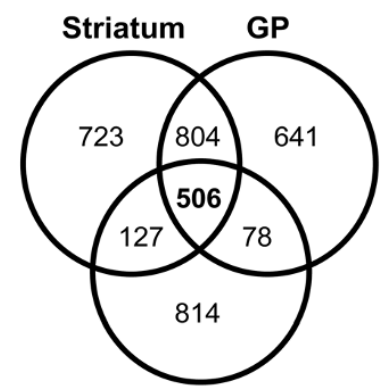

Olfactory bulb

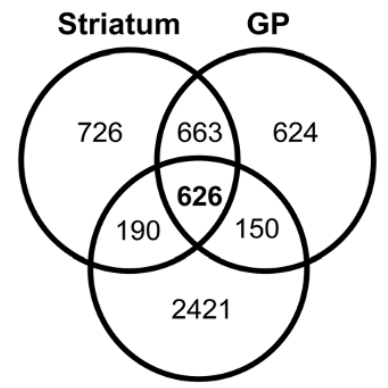

Substantia nigra
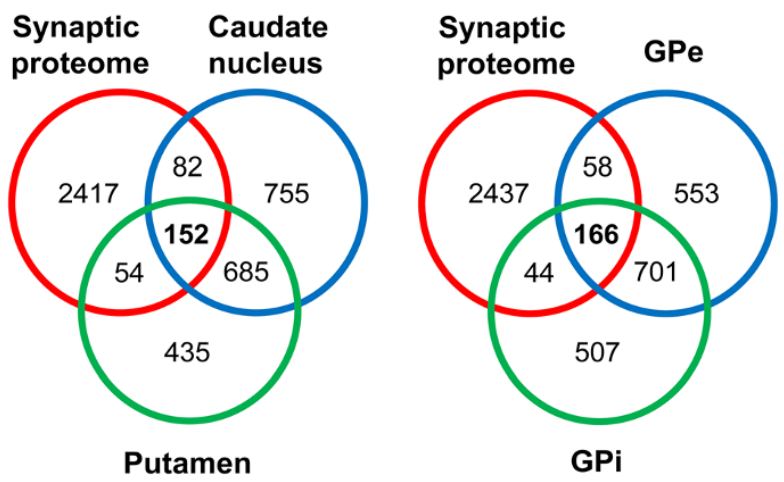

Figure 4 Intersection of proteins derived from proteomic expression profiling of human limbic structures and synaptosomes with proteins identified in BG nuclei. (upper) Protein expression data reported in amygdala [35], hippocampus [36], olfactory bulb [37], pituitary gland [38], thalamus [39], and sustantia nigra [26,28,40-42] have been considered. Striatum dataset contains proteins detected in CN and putamen while GP dataset encompasses proteins identified in the lateral and medial segments (GPe and GPi). Numbers represent the number of shared proteins in the respective overlapping areas. (lower) Venn diagrams representing the overlap between the "synaptic proteome" composed by the three major databases on synaptic proteins (C2G, SynsysNet, and Synaptome DB) [43-45] and the striatal and pallidal proteomes characterized in this study.

reactions using the PANTHER classification system [48]. Interestingly, as shown in Figure 5, some statistically over-represented processes in both structures were directly relevant to neurotransmitter release, electrical machinery and synaptic plasticity (Additional file 13: Table S12). Specifically, we found a significant enriched pathway focused on gamma-aminobutyric acid (GABA) synthesis in pallidal dataset while in the case of striatum, most of enriched pathways are related to beta-adrenergic receptors and endogenous opioid system. The observation that there are protein clusters differentially enriched between striatal and pallidal structures related to specific biological process and molecular function ontologies is not relevant since all protein clusters were represented in both structures but their statistics did not reach the minimum statistical requirements.

\section{BG proteomics as a complement of the human brain} transcriptome

We have correlated our proteomic fingerprints with the anatomical map of the human brain transcriptome stored in the Allen Brain Atlas [11] in order to analyze 


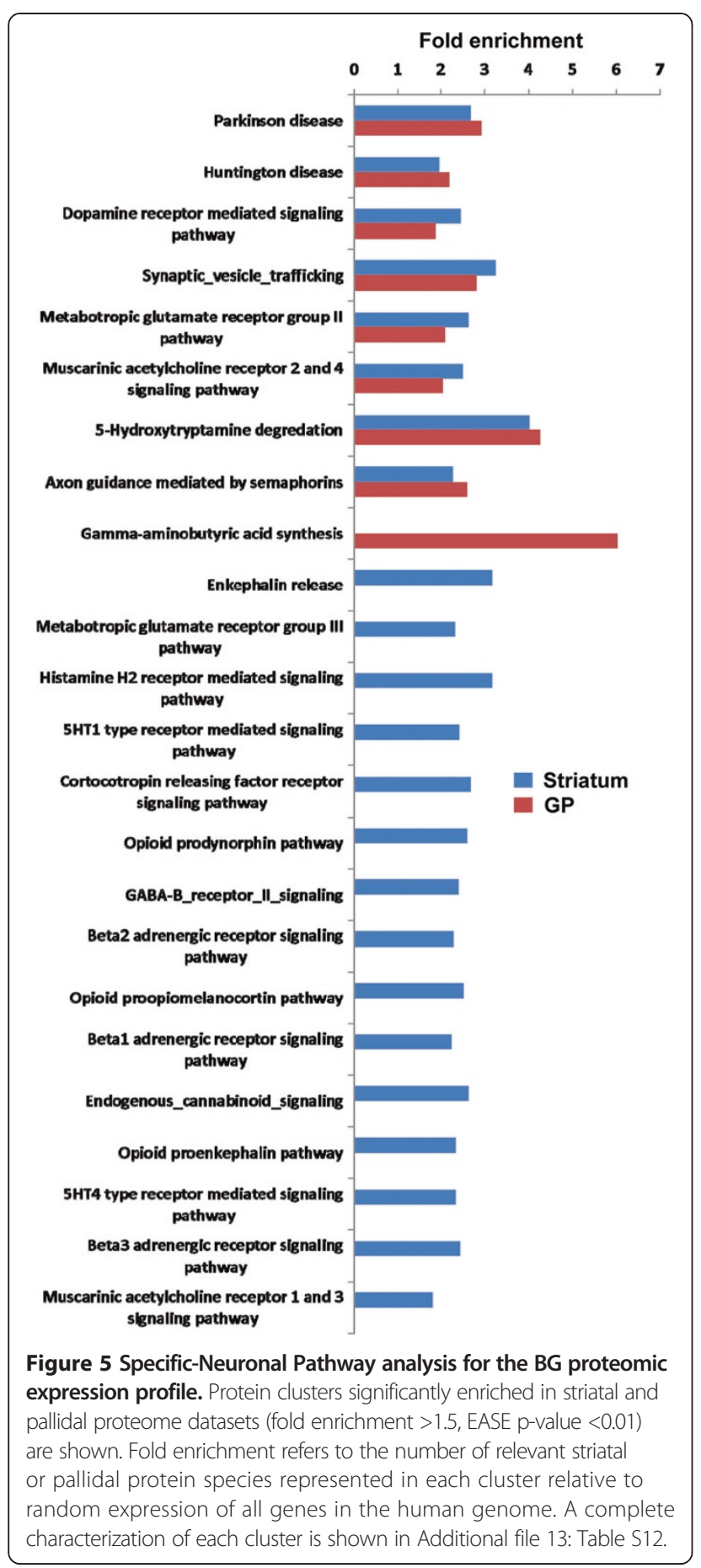

the interrelationship of expressed genes and proteins at different levels of organization. First, we have interlocked each BG proteomic expression profiling with transcriptomic data from genes with brain-wide (global) or within structure (local) ubiquity (Figure 6 and Additional file 14: Table S13). Second, transcriptome expression data from genes specifically expressed in striatum and globus pallidus [11] was checked against the anatomo-proteomic expression data derived from BG structures (Figure 6 and Additional file 14: Table S13). As shown in Figure 6, we have detected pallidal protein expression for 81 and 86 genes (in GPe and GPi respectively) and striatal protein expression for 100 and 75 genes (in $\mathrm{CN}$ and putamen respectively) with ubiquitous expression across human brain (Additional file 14: Table S13). In contrast, proteomic screens have revealed pallidal protein expression for nearly 40 genes with region-specific expression, whereas in the case of striatum, we have obtained protein expression data for 49 and 42 region-specific genes in $\mathrm{CN}$ and putamen respectively (30 genes common in both structures) (Figure 6 and Additional file 14: Table S13). From 172 regionspecific genes that express in globus pallidus, we have obtained protein evidence for 5 and 7 genes in GPe and GPi respectively (4 common proteins in both structures) whereas 13 out of 160 region-specific genes that express in striatum have been detected at protein level in $\mathrm{CN}$ ( 9 genes in the case of putamen) (Figure 6 and Additional file 14: Table S13).

Specific protein products of major cell type markers in BG datasets

Additional analyses were performed to detect cell typespecific information in BG by detecting protein evidence for well-known transcriptomic markers of major cell classes [49,50]. Protein expression of marker genes of oligodendrocytes (CNP, HSPA2, MBP, MOG, PLP1), astrocytes (ATP1A2, GFAP, GLUL, HAPLN1, SLC4A4, AHCYL1), and neurons (PGM2L1, GDA, MAP2, $M A P 1 B, S C G 2$, SNAP25) was detected in all four structures (Table 1). In addition, protein products of other oligodendrocyte marker genes such as BCAS1, ENPP6, and $P P P 1 R 14 A$ were found in pallidal structures. Protein expression was also detected for additional astrocyte markers such as SLC1A2 (in GPe, GPi, and putamen), $A L D O C$ (in GPi, CN, and putamen), METTL7A (in GPi and putamen), and ALDH1L1 in CN. Respect to neuronal markers, protein products for PLCXD3, SLC12A5, NRCAM, and NRXN1 genes were also identified across striatal and/or pallidal structures (Table 1).

\section{Discussion}

The complex structural and functional organization of the brain is reflected by the selective spatial and temporal expression of its resident proteins [10]. Given its segmented functions, characterization of protein profiles within specific regions of the adult brain forms an essential part of unearthing the molecular basis for structure specialization and perturbation associated with neurological disorders.

In this work, we have performed an anatomically comprehensive proteomic mapping of human BG in order to gain new insight into the protein content and protein 


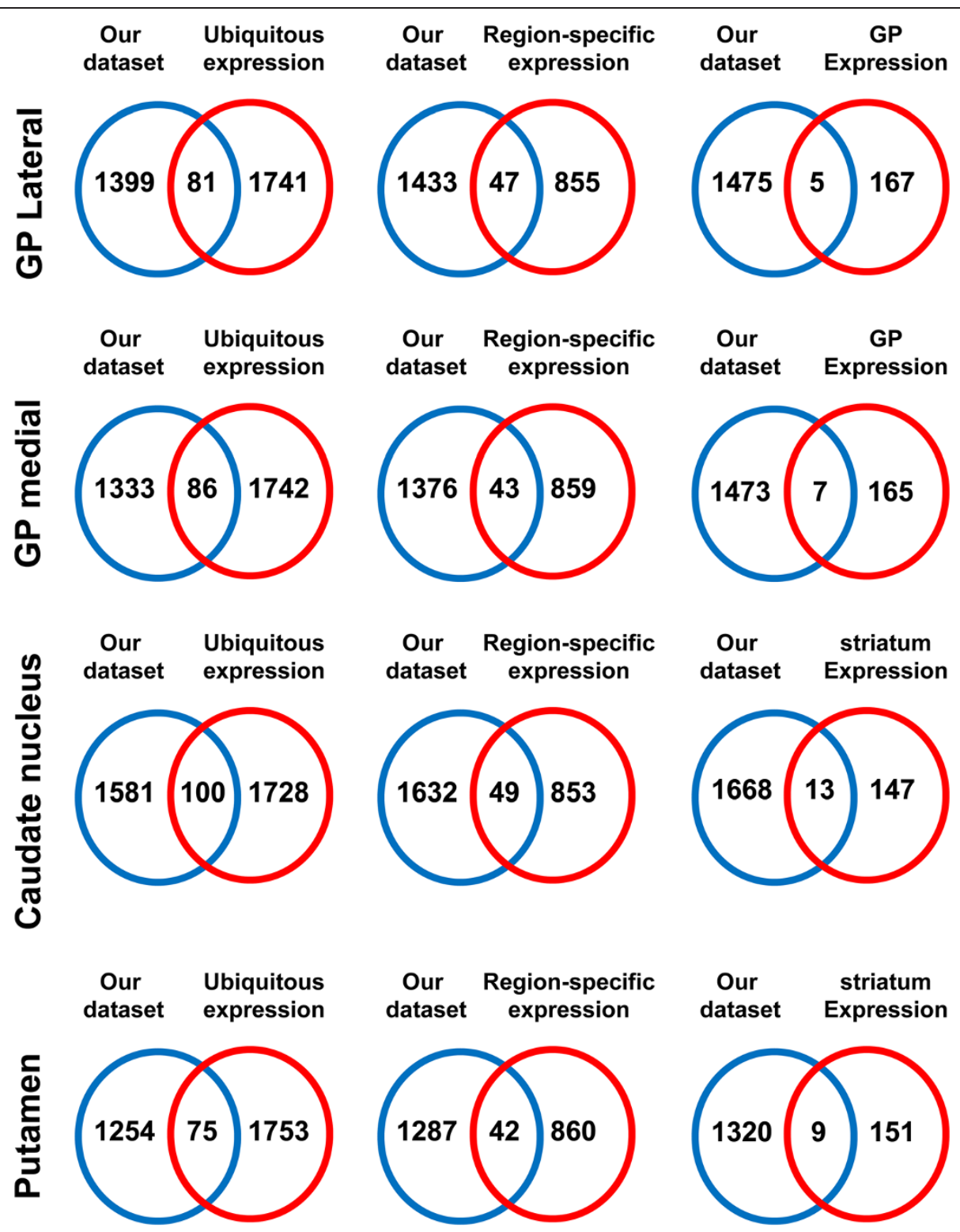

Figure 6 Anatomical correlation between pallidal and striatal proteomic expression profiling and human brain transcriptome. Protein datasets derived from BG structures were intersected with transcriptomic expression profiling obtained in human brain [11]. In this case, we have considered genes with brain-wide expression (ubiquitous expression) or within local ubiquity (region-specific expression) in neocortex, myelencephalon, hippocampal formation, dorsal thalamus, striatum, mesencephalon, cerebellar cortex, pontine tegmentum, cingulate gyrus, basal pons, claustrum, and globus pallidus [11]. See Additional file 14: Table S13 for more details.

function of striatal and pallidal nuclei. Using complementary protein and peptide fractionation methods coupled to tandem mass spectrometry, we have identified 2979 unique proteins in BG corresponding to more than 5900 protein expression features distributed across $\mathrm{CN}$, putamen, GPe, and GPi.

Although striatal and pallidal structures are composed by different specialized types of neurons with highly distinct transcriptomic profiles $[6,7,11]$, more than 500 proteins have been commonly detected in $\mathrm{CN}$, putamen, GPe, and
GPi structures. This panel of proteins takes part in a global protein interactome map, indicating that oxidative phosphorylation, protein degradation, and neurotrophin signalling are active pathways mediated by overlapping protein interactors in striatal and pallidal structures.

Although our study has uncovered many intricacies in protein expression in BG, there are potential limitations of our study that warrant discussion. We analysed dissected tissues that contained multiple cell types, thus diluting the proteomic contribution of any one specific 
Table 1 Detection of specific protein products of major cell type markers in basal nuclei by proteomics

\begin{tabular}{|c|c|c|c|c|c|c|}
\hline Markers & Protein products & Code & Gpe & Gpi & $\mathrm{CN}$ & Put. \\
\hline \multicolumn{7}{|l|}{ OLs } \\
\hline CNP & 2',3'-cyclic-nucleotide 3'-phosphodiesterase & P09543 & ++ & ++ & ++ & ++ \\
\hline HSPA2 & Heat shock-related $70 \mathrm{kDa}$ protein 2 & P54652 & ++ & ++ & ++ & ++ \\
\hline MOG & Myelin oligodendrocyte glycoprotein & Q5STM1 & ++ & ++ & ++ & ++ \\
\hline$P L P 1$ & Proteolipid protein 1 & A8K9L3 & ++ & ++ & ++ & ++ \\
\hline \multirow[t]{2}{*}{$M B P$} & Isoform 3 of Myelin basic protein & P02686-3 & ++ & --- & ++ & ++ \\
\hline & Myelin basic protein & P02686 & --- & ++ & --- & --- \\
\hline BCAS1 & Isoform 2 of Breast carcinoma-amplified sequence 1 & 075363-2 & ++ & --- & --- & --- \\
\hline ENPP6 & Ectonucleotide pyrophosphatase/phosphodiesterase member 6 & Q6UWR7 & --- & ++ & --- & --- \\
\hline PPP1R14A & Protein phosphatase 1 regulatory subunit 14A & Q96A00 & --- & ++ & --- & --- \\
\hline \multicolumn{7}{|c|}{ Astrocytes } \\
\hline ATP1A2 & Sodium/potassium-transporting ATPase subunit alpha-2 & B1AKY9 & ++ & ++ & ++ & ++ \\
\hline GFAP & Glial fibrillary acidic protein & P14136 & ++ & ++ & ++ & ++ \\
\hline GLUL & Glutamate-Ammonia Ligase & A8YXX4 & ++ & ++ & ++ & ++ \\
\hline HAPLN1 & Hyaluronan and proteoglycan link protein 1 & P10915 & ++ & ++ & ++ & ++ \\
\hline AHCYL1 & Putative adenosylhomocysteinase 2 & O43865 & ++ & ++ & ++ & ++ \\
\hline ALDOC & Fructose-bisphosphate aldolase C & P09972 & --- & ++ & ++ & ++ \\
\hline \multirow[t]{3}{*}{ SLC4A4 } & Solute carrier family $4 \mathrm{Na}(+) / \mathrm{HCO} 3(-)$ cotransporter 4 isoform 2 & Q9Y6R1-2 & ++ & --- & ++ & --- \\
\hline & Solute carrier family $4 \mathrm{Na}(+) / \mathrm{HCO}(-)$ cotransporter 4 & Q9Y6R1 & --- & --- & --- & ++ \\
\hline & Solute carrier family $4 \mathrm{Na}(+) / \mathrm{HCO} 3(-)$ cotransporter 4 variant & A5JJ20 & --- & ++ & --- & --- \\
\hline \multirow[t]{2}{*}{ SLCIA2 } & Excitatory amino acid transporter 2 & P43004 & ++ & ++ & --- & --- \\
\hline & Solute carrier family 1 , member 2 & $\mathrm{~A} 2 \mathrm{~A} 2 \mathrm{U} 1$ & --- & --- & --- & ++ \\
\hline METTLTA & Methyltransferase-like protein 7A & Q9H8H3 & --- & ++ & --- & ++ \\
\hline ALDH1L1 & Cytosolic 10-formyltetrahydrofolate dehydrogenase & O75891 & --- & -- & ++ & --- \\
\hline \multicolumn{7}{|l|}{ Neurons } \\
\hline PGM2L1 & Glucose 1,6-bisphosphate synthase & Q6PCE3 & ++ & ++ & ++ & ++ \\
\hline \multirow[t]{2}{*}{ GDA } & Guanine deaminase & Q9Y2T3 & ++ & ++ & --- & ++ \\
\hline & Guanine deaminase isoform 3 & Q9Y2T3-3 & --- & -- & ++ & --- \\
\hline \multirow[t]{2}{*}{ MAP2 } & Isoform 3 of Microtubule-associated protein 2 & P11137-3 & ++ & ++ & ++ & ++ \\
\hline & MAP2 protein (Fragment) & Q6NYC5 & ++ & ++ & ++ & ++ \\
\hline MAP1B & Microtubule-associated protein 1B & P46821 & ++ & ++ & ++ & ++ \\
\hline SCG2 & Secretogranin-2 & P13521 & ++ & ++ & ++ & ++ \\
\hline SNAP25 & Synaptosomal-associated protein 25 & P60880 & ++ & ++ & ++ & ++ \\
\hline \multirow[t]{3}{*}{ SLC12A5 } & Solute carrier family 12 member 5 & Q9H2X9 & ++ & --- & --- & --- \\
\hline & CDNA FLJ75342, similar to solute carrier family 12 member 5 & A8K143 & --- & ++ & ++ & ++ \\
\hline & Isoform SNAP-25a of Synaptosomal-associated protein 25 & P60880-2 & --- & --- & ++ & ++ \\
\hline PLCXD3 & similar to Pl-specific phospholipase $\mathrm{C}, \mathrm{X}$ domain containing 3 & B3KXD1 & ++ & --- & ++ & ++ \\
\hline \multirow[t]{2}{*}{ NRCAM } & Isoform 2 of Neuronal cell adhesion molecule & Q92823-2 & --- & ++ & --- & -- \\
\hline & Neuronal cell adhesion molecule & Q92823 & --- & --- & -- & ++ \\
\hline NRXN1 & Neurexin-1-alpha & Q9ULB1 & --- & -- & ++ & ++ \\
\hline
\end{tabular}

$(++)$ indicates protein evidence and (---) non-detected. Code refers to the UniProtKB/Swiss-Prot entry for each protein. OLs, Oligodendrocytes.

cell type. Furthermore, the number of structures analysed so far is not sufficient to investigate the full magnitude of proteomic expression in BG. Moreover, we have employed pooled samples for each independent substructure. Although all individuals were males of similar age and ethnicity, our data do not capture population or sex 
diversity. Taking into account that human brain transcriptome is highly dynamic during neurodevelopment $[10,11]$, additional proteomic studies employing post-mortem brains of clinically unremarkable donors representing males and females with different ages and ethnic backgrounds are necessary to estimate the consistency of the proteomic profile obtained in this study.

One of the goals of the present study was to generate extensive and robust data on the functional groups of proteins present in human BG. To identify biologically relevant pathways from large-scale BG proteome data, we have undertaken a system biology approach performing different molecular network and pathways analysis using gene ontologies, KEGG pathways, and PANTHER classification system [46-48]. Although each bioinformatics platform produced diverse results, they commonly point out that tricarboxylic acid cycle, ubiquitin proteasome pathway and energy metabolism are the general over-represented processes in basal nuclei as might be expected given the high metabolic demands of neurons.

In agreement with different brain proteomic studies $[32,35,37]$, a high proportion of identified proteins present catalytic and binding activities. We have not detected a clearly distinguishable pattern of molecular categories between striatal and pallidal structures. Several reasons may explain the functional parallelism observed in both structures. First, our workflow is based on analysing un-fractionated tissue homogenates using a QTRAP instrument [51] without employing previous sequential extraction of proteins (for example enriched organelle fractions, synaptosomes, etc.). This implies that our proteomic datasets may correspond to highly abundant proteins and housekeeping enzymes and tend to represent the majority of proteins identified in unfractionated neural tissue, hampering the identification of less abundant proteins with functional relevance. Future studies employing high-resolution instruments will increase the quality of BG proteome data in terms of high resolving power, mass accuracy, and high sequencing speed, generating novel proteomic data with high impact from a functional point of view [52,53]. Second, a high proportion (30\%) of pallidal and striatal proteomes encompasses uncharacterized, putative or predicted proteins based on genomic sequence data, limiting the extraction of functional information from bioinformatics resources. This is in accordance with data obtained in human cortex, thalamus, and amygdala where also more than $20 \%$ of the proteins identified by shotgun proteomic methods could not be assigned to biological processes $[32,35,39,54]$. However, we have obtained a cell type-specific information in basal nuclei identifying protein products for well-known markers of major cell classes derived from large-scale transcriptomic studies $[49,50]$ indicating that shotgun proteomic approaches may be useful to identify specific protein isoforms of cell markers, obtaining complementary information that adds value to the conventional detection by immunohistochemical staining.

We wish to emphasize that even though certain proteins were identified in a particular BG structure, this does not necessarily imply their absence in other nuclei (see Additional file 15: Figure S7). Our data indicate that a considerable proportion of this protein list was identified with a low number of peptides suggesting that the discovery of this subset of proteins in a specific region may be due to technical bias rather than specific protein enrichment with respect to other structures.

We have obtained a deep functional analysis of the striatum and globus pallidus, detecting a plethora of neuronal molecular events enriched in basal nuclei. In agreement with high throughput proteomic analyses of other brain regions [32,37], enriched functional categories focused on carbohydrate, lipid, and amino acid metabolism were also detected in striatum and globus pallidus. In addition, we have found a considerable proportion of proteins (11\% of the dataset) that tends to localize to synaptic terminal suggesting a potential role in the regulation of synaptic transmission and neurotransmitter transport. For example, functional analyses allowed us to classify different set of proteins in specificneuronal pathways across pallidal and striatal structures such as serotonin degradation (8 proteins), dopamine receptor (30 proteins), metabotropic glutamate receptor (18 proteins), muscarinic acetylcholine receptor (22 proteins), and endogenous opioid system (10 proteins).

In order to expand our knowledge about the global system biology of human brain, we interlocked regional transcriptomic and proteomic signatures by focusing our analyses on genes with global or local ubiquity [11]. Our anatomo- proteomic analysis partially complements the human brain transcriptome since we have obtained protein expression data for an appreciable number of genes with proven transcriptomic evidence in basal nuclei and other structures across the human brain. Specifically, qualitative proteomics allow us to detected protein expression (in GPe and GPi structures) for 8 genes (Thiomorpholine-carboxylate dehydrogenase, RuvB-like 2, Calcium/calmodulin-dependent $3^{\prime}, 5^{\prime}$-cyclic nucleotide phosphodiesterase 1B, Hyaluronan and proteoglycan link protein 1, Neuronal pentraxin-1, Synaptic vesicle glycoprotein 2B, Ephrin type-A receptor 6 and CaM kinase-like vesicle-associated protein) that tend to be differentially regulated between both pallidal structures [11].

On the other hand, in silico analysis points out that nearly $4 \%$ of identified proteins in BG have been previously associated to neurodegenerative syndromes, and $20 \%$ of identified proteins were also localized in cerebrospinal fluid (CSF) from healthy subjects [33,55]. From 
the point of view for biomarker discovery, it is crucial to identify the presence of brain tissue analytes in CSF, a readily accessible resource for biomarker development pipelines. Therefore, this comprehensive BG protein dataset may serve as a reference list of human BG proteome for biomarker research of movement disorders and other neurodegenerative diseases, being a useful resource to establish quantitative targeted analysis of potential BG protein biomarkers by MRM (Multiple Reaction Monitoring) assays [56,57].

\section{Conclusions}

We have carried out, to the best of our knowledge, the first comprehensive analysis of the proteome present in human caudate nucleus, putamen, GPe, and GPi. Our results provide a broad functional analysis of 2979 nonredundant striatal and pallidal proteins, being the first step toward the complete characterization of the tangled molecular architecture that composes de BG. This molecular fingerprint together with previous proteomic profiling of specialized brain regions [32,35-39,54,58-61] contribute to the repertoire of the human brain proteome, providing fundamental information for the recently officially launched Human Proteome Project and the BRAIN Initiative $[62,63]$. Taking into account that the central nervous system poses many specific challenges in terms of proteomics, given the large number of different neuronal cell types that are intermixed and that exhibit distinct patterns of gene and protein expression $[10,11,64]$, the development of specific isolation protocols of single-cell types together with novel developments in shotgun proteomic strategies [65] will allow to explore the proteome profiling of each subcortical nucleus individually, boosting the molecular knowledge of the BG.

\section{Methods}

\section{Sample collection}

According to the Spanish Law 14/2007 of Biomedical Research, inform written consent form of the Neurological Tissue Bank of Navarra Health Service was obtained for research purposes from relatives of patients included in this study. The 6 patients were male and ages ranged from 29 to 61 years, with no known neuropsychiatric or neurological history (control cases) (Additional file 7: Figure S1). According to standard practices in place at the neurological tissue banks, the left cerebral hemisphere was progressively frozen and stored at $-80^{\circ} \mathrm{C}$ (post-mortem-interval: 6-15 h). The diagnosis was carried out on the left cerebral hemisphere. Therefore, the BG assessed in this study were the right ones. Following fixation in $10 \%$ formaldehyde for approximately three weeks, the brains were sectioned according to the recommendation guide proposed by BrainNet Europe [66]. After a macroscopic study, immunohistochemistry analysis was performed in different brain regions using specific antibodies against Tau protein, $\beta$ amyloid, TDP-43, PrP, $\alpha$-synuclein, ubiquitin and $\alpha-\beta$ crystalline. These brains did not show significant pathology and were considered to be healthy. In particular, the immunohistochemical study of the BG showed normal tissue without appreciable abnormalities. The recognition of basal ganglia structure by the neuropathologists was as follows: the caudate nucleus $(\mathrm{CN})$ is a C-shaped structure that is closely associated with the lateral wall of the lateral ventricle. The putamen is also a large structure that is separated from the $\mathrm{CN}$ by the anterior limb of the internal capsule. The globus pallidus (GP) is divided into two segments: the internal (or medial) segment and the external (or lateral) segment. Both are separated by the medial medullary lamina. The GP is separated from the putamen by a thin layer of white matter called the lateral medullary lamina. A representative image of BG is shown in Additional file 7: Figure S2.

\section{Sample preparation for proteomic analysis}

BG specimens were obtained from frozen brain sections using sterile biopsy punches (size: $3-4 \mathrm{~mm}$ ) and homogenized in lysis buffer containing $7 \mathrm{M}$ urea, $2 \mathrm{M}$ thiourea, 4\% (w/v) CHAPS, $50 \mathrm{mM}$ DTT. The homogenates were spinned down at $100.000 \times \mathrm{g}$ for $1 \mathrm{~h}$ at $15^{\circ} \mathrm{C}$. Protein concentration was measured in the supernatants with the Bradford assay kit (Biorad). Prior to proteomic analysis, the individual BG samples were grouped into 4 independent pools (GPe, GPi, putamen, and $\mathrm{CN}$ ) containing $\sim 120 \mu \mathrm{g}$ of protein from 6 individual samples each one.

\section{Peptide fractionation by HPLC}

Protein material was precipitated using methanol/ chloroform. Pellets $(\sim 700 \mu \mathrm{g} / \mathrm{pool})$ were dissolved in $100 \mathrm{mM}$ Tris, pH 7.8, and $6 \mathrm{M}$ urea. Reduction was performed by addition of DTT to a final concentration of $10 \mathrm{mM}$ and incubation at $25^{\circ} \mathrm{C}$ for $1 \mathrm{~h}$. Subsequent alkylation by $30 \mathrm{mM}$ iodoacetamide was performed for $1 \mathrm{~h}$ in the dark. An additional reduction step was performed by $30 \mathrm{mM}$ DTT, allowing the reaction to stand at $25^{\circ} \mathrm{C}$ for $1 \mathrm{~h}$. Proteins were digested for $4 \mathrm{~h}$ with Lys$\mathrm{C}$ (Promega) at $37^{\circ} \mathrm{C}$ (enzyme:protein, 1:140 w/w). The mixtures were then diluted to $0.6 \mathrm{M}$ urea using MilliQwater, and after trypsin addition (Promega) (enzyme:protein, $1: 50 \mathrm{w} / \mathrm{w})$, the sample was incubated at $37^{\circ} \mathrm{C}$ for $18 \mathrm{~h}$. Digestion was quenched by acidification with acetic acid. The digestion mixture $(\sim 350 \mu \mathrm{g}$ protein) was dried in a SpeedVac, reconstituted with 40ul of $5 \mathrm{mM}$ ammonium bicarbonate $(\mathrm{ABC}) \mathrm{pH} 9.8$, and injected to an Ettan LC system with a high $\mathrm{pH}$ stable X-Terra RP18 column (C18; $2.1 \mathrm{~mm} \times 150 \mathrm{~mm} ; 3.5 \mu \mathrm{m}$ ) (Waters) at a flow rate of $40 \mu \mathrm{l} / \mathrm{min}$. Peptides were eluted with a 
mobile phase $B$ of $5-65 \%$ linear gradient over $35 \mathrm{~min}$ (A, $5 \mathrm{mM} \mathrm{ABC}$ in water at $\mathrm{pH} 9.8 ; \mathrm{B}, 5 \mathrm{mM} \mathrm{ABC}$ in acetonitrile at $\mathrm{pH}$ 9.8). 16-18 fractions were collected, evaporated under vacuum and reconstituted into $15 \mu \mathrm{l}$ of $2 \%$ acetonitrile, $0.1 \%$ formic acid, $98 \%$ water.

\section{Protein fractionation by isoelectric focusing (IEF)}

Approximately $500 \mu \mathrm{g}$ of each pooled sample was precipitated with methanol/chloroform. The pellet were resuspended in $300 \mu \mathrm{l}$ of IEF rehydration buffer $(7 \mathrm{M}$ urea, $2 \mathrm{M}$ thiourea, 2\% CHAPS, $50 \mathrm{mM}$ DTT, 0.5\% Bio-Lyte 3/10 ampholyte) and loaded on $17 \mathrm{~cm} \mathrm{pH} \mathrm{3-10} \mathrm{IPG}$ strip in a focusing tray. Isoelectric focusing was performed on a Bio-Rad PROTEAN IEF system (Bio-Rad). Conditions for performing IEF were as follows: after rehydration of the IPG strip for $12 \mathrm{~h}$ at $50 \mathrm{~V}$ and $20^{\circ} \mathrm{C}$, the run was started at $250 \mathrm{~V}$ for $15 \mathrm{~min}$. followed by rapid voltage ramping to $8000 \mathrm{~V}$ without exceeding $50 \mathrm{~A} /$ strip. The IEF run was finished when the voltage reached $35,000 \mathrm{Vhr}$. The voltage was held at $500 \mathrm{~V}$ until the run was stopped. The IEF run was performed at $20^{\circ} \mathrm{C}$. Each entire IPG strip was divided into 25 equal parts $(\sim 0.7 \mathrm{~cm}$ each) for in-gel reduction, alkylation, and digestion. In-gel tryptic digestion was performed with $20 \mathrm{ng} / \mu \mathrm{l}$ trypsin in $50 \mathrm{mM}$ ammonium bicarbonate for $12 \mathrm{~h}$ at $37^{\circ} \mathrm{C}$. The resulting tryptic peptides were extracted with $5 \%$ formic acid, $50 \%$ acetonitrile and 5\% formic acid, $85 \%$ acetonitrile. Peptide mixtures were completely dried in a SpeedVac and resuspended in $20 \mu \mathrm{l} 98 \%$ MilliQ- $\mathrm{H}_{2} \mathrm{O}, 2 \%$ acetonitrile, and $0.1 \%$ formic acid.

\section{nanoLC-MS/MS analysis}

For each fraction, a total volume of $5 \mu \mathrm{l}$ of tryptic peptides was injected with a flow rate of $300 \mathrm{~nL} / \mathrm{min}$ in a nanoLC Ultra1D plus (Eksigent). The column and the autosampler were maintained at a temperature of $40^{\circ} \mathrm{C}$ and $4^{\circ} \mathrm{C}$ respectively. A trap column Acclaim PepMap100 (100 $\mu \mathrm{m} \times 2 \mathrm{~cm} ; \mathrm{C} 18,5 \mu \mathrm{m}, 100 \AA)$ and an analytical column Acclaim PepMap RSLC $(75 \mu \mathrm{m} \times 15 \mathrm{~cm}$, C18, $2 \mu \mathrm{m}, 100 \AA$ ) (Dionex) were used following the next gradient: $0-1 \mathrm{~min}$ ( $2 \%$ Buffer B), 1-110 min (230\% Buffer B), 110-120 min (30-40\% Buffer B), 120125 min (40-90\% Buffer B), 125-130 min (90\% Buffer B), $130-132 \mathrm{~min}$ (90-2\% Buffer B) and 132-150 min (2\% Buffer B) (Buffer B (100\% acetonitrile, 0.1\% formic acid), Buffer A (0.1\% formic acid)). MS analysis was performed on a Q-TRAP 5500 system (ABSciex) with a NanoSpray ${ }^{\oplus}$ III ion source (ABSciex). The mass spectrometer was operated in positive ion mode at unit resolution. Each fraction was analyzed twice in technical replicates. For MS/MS analysis, survey scans were acquired from $\mathrm{m} / \mathrm{z}$ 400 to 1000 with up to 6 precursors selected for MS/MS from $\mathrm{m} / \mathrm{z} 230$ to 1000 using dynamic exclusion, and the rolling collision energy was used to promote fragmentation. MS/MS data acquisition was performed using Analyst 1.5.2 (AB Sciex) and spectra files were processed through Protein Pilot ${ }^{\mathrm{TM}}$ Software (v.4.0.8085ABSciex) using Paragon ${ }^{\mathrm{TM}}$ Algorithm (v.4.0.0.0) for database search against the concatenated target-decoy UniProt human database (Database: uniprot_sprot_20100622). For each substructure, 82-86 runs were processed sequentially with output files for each individual fraction and a merged, non-redundant output file generated for protein identifications. To minimize the false positive identification of proteins, an unused ProtScore $\geq 2$ (corresponding to $99 \%$ confidence) was used as the qualification criteria. False discovery rate (FDR) was performed using a nonlineal fitting method [67] and displayed results were those reporting a protein level-FDR lower than $1 \%$. The mass spectrometry proteomics data have been deposited to the ProteomeXchange Consortium (http://proteomecentral. proteomexchange.org) via the PRIDE partner repository [68] with the data set identifier PXD000742 for the CN, PXD000749 for the putamen, PXD000755 for the GPe, and PXD000757 for the GPi.

\section{Data handling and bioinformatic analysis}

The proteins identified in this study were classified by DAVID (Database for Annotation, Visualization and Integrated Discovery) Bioinformatics Resources (v6.7) [46], where proteins are assigned in gene ontology (GO) terms, which rely on a controlled vocabulary for describing a protein in terms of its molecular function, biological process, or subcellular localization [69]. For functional annotation clustering, we set the following parameters: "Biological process and molecular function", high stringency and EASE p-value <0.01. PANTHER (Protein annotation through evolutionary relationship) classification system (http://www.pantherdb.org/) [48] was used to perform proteome mapping analysis of BG proteins across specific-neuronal processes. Network analysis was performed submitting the corresponding protein IDs to the STRING (Search Tool for the Retrieval of Interacting Genes) software (v.9.1) (http:// stringdb.org/) [34]. This is a large database of known and predicted protein interactions. Proteins were represented with nodes and the interactions with continuous lines to represent direct interactions (physical), while indirect ones (functional) were presented by interrupted lines. All the edges were supported by at least a reference from the literature or from canonical information stored in the STRING database. To minimize false positives as well as false negatives, only interactions tagged as "high confidence" (>0.7) in STRING database were considered. Protein/gene ID conversions were obtained using g:profiler (http://biit.cs.ut.ee/gprofiler/gconvert.cgi) [70] and Protein Identifier Cross-Reference tool (PICR) (http://www.ebi.ac.uk/Tools/picr/) [71]. 


\section{Additional files}

\section{Additional file 1: Proteins identified in Caudate Nucleus (CN). \\ Additional file 2: Proteins identified in Putamen. \\ Additional file 3: Proteins identified in Lateral Globus Pallidus (GPe)}

Additional file 4: Proteins identified in Medial Globus Pallidus (GPi). Additional file 5: Genetic Association Database results.

Additional file 6: Functional analysis of basal ganglia proteins previously detected in CSF.

Additional file 7: Figure S1. General characteristics of the subjects included in the proteomic study. Figure S2. A representative image of BG structures analyzed in this study. Figure S3. Basal ganglia protein interactome network. Figure S4. Representative biological process categories from each cluster in striatal and pallidal structures. Figure S5. Representative molecular function categories from each cluster in striatum and globus pallidus. Figure S6A. Cellular Component Ontology for the striatal and pallidal proteomic expression profiles. Classification of BG proteomes based on cellular localization. Figure S6B. Cellular Component Ontology for the striatal and pallidal proteomic expression profiles. Neuron-specific localization detected by DAVID software.

Additional file 8: Protein-protein interactions for the common proteome detected in Gpe, Gpi, CN y putamen using the STRING software.

Additional file 9: Compilation of synaptic proteome databases. Synaptic proteome detected in basal ganglia structures.

Additional file 10: Significantly enriched categories in Biological Process Ontology.

Additional file 11: Significantly enriched categories in Molecular Function and Cellular Component Ontologies.

Additional file 12: KEGG pathways analysis of basal ganglia proteome datasets.

Additional file 13: Striatal and pallidal proteome distributions across specific reactions using the PANTHER classification system.

Additional file 14: Anatomical correlation between pallidal and striatal proteomic expression profiling and human brain transcriptome.

Additional file 15: Immunohistochemical analysis of Excitatory Amino Acid Transporter 2 and A-Kinase anchor protein 12 in striatal and pallidal structures.

\section{Abbreviations}

BG: Basal ganglia; CN: Caudate nucleus; IEF: Isoelectric focusing; SN: substantia nigra; GP: Globus pallidus; GPi: Medial globus pallidus; GPe: Lateral globus pallidus; STN: Subthalamic nucleus; MS: Mass spectrometry; NanoLC-MS/MS: Nano-liquid chromatography tandem mass spectrometry; 2-DE: Bidimensional electrophoresis.

\section{Competing interests}

The authors declare that the research was conducted in the absence of any commercial or financial relationships that could be construed as a potential conflict of interest.

\section{Authors' contributions}

JFI designed, carried out experiments, analysed data and wrote the paper. MVZ performed the neuropathological diagnosis, selected the human tissues, and processed the brain specific regions. TT performed the neuropathological diagnosis, and selected the human tissues. ES conceived the project, designed, carried out experiments, analysed data and wrote the paper. All authors read and approved the final manuscript.

\section{Acknowledgements}

We thank the Neurological Tissue Bank of Navarra Health Service for providing us the basal ganglia specimens and for sharing experiences on human brain processing. The technical assistance of Valle Coca in immunohistochemical analysis is acknowledged. Authors thank all PRIDE Team for helping with the mass spectrometric data deposit in

ProteomeXChange/PRIDE. This project is part of the HUPO Brain Proteome Project. Navarrabiomed Proteomics Unit belongs to ProteoRed, PRB2-ISCIII, supported by grant PT13/0001, and is member of the Spanish Human Proteome Project (SpHPP) (Chromosome 16 Consortium).

\section{Author details}

${ }^{1}$ Clinical Neuroproteomics Group, Proteomics Unit, Proteored-ISCIII, Navarrabiomed, Fundación Miguel Servet, Irunlarrea Street, 31008 Pamplona Spain. ${ }^{2}$ Neurological Tissue Bank, Navarrabiomed, Fundación Miguel Servet, 31008 Pamplona, Spain. ${ }^{3}$ Pathological Anatomy Department, Navarra Hospital Complex, Pamplona, Spain.

Received: 26 June 2014 Accepted: 4 November 2014 Published online: 18 November 2014

\section{References}

1. Takakusaki K, Saitoh K, Harada H, Kashiwayanagi M: Role of basal ganglia-brainstem pathways in the control of motor behaviors. Neurosci Res 2004, 50:137-151.

2. Turner RS, Desmurget M: Basal ganglia contributions to motor control: a vigorous tutor. Curr Opin Neurobiol 2010, 20:704-716.

3. Chesselet MF, Delfs JM: Basal ganglia and movement disorders: an update. Trends Neurosci 1996, 19:417-422.

4. Alexander GE, DeLong MR, Strick PL: Parallel organization of functionally segregated circuits linking basal ganglia and cortex. Annu Rev Neurosci 1986, 9:357-381.

5. Obeso JA, Rodriguez-Oroz MC, Benitez-Temino B, Blesa FJ, Guridi J, Marin C Rodriguez M: Functional organization of the basal ganglia: therapeutic implications for Parkinson's disease. Mov Disord 2008, 23(Suppl 3):S548-S559.

6. Graybiel AM: Neurotransmitters and neuromodulators in the basal ganglia. Trends Neurosci 1990, 13:244-254.

7. Lanciego $\mathrm{J}$, Luquin $\mathrm{N}$, Obeso JA: Functional neuroanatomy of the basal ganglia. Cold Spring Harb Perspect Med 2012, 2:a009621.

8. Bonsi P, Cuomo D, Martella G, Madeo G, Schirinzi T, Puglisi F, Ponterio G, Pisani A: Centrality of striatal cholinergic transmission in Basal Ganglia function. Front Neuroanat 2011, 5:6

9. Bayes A, Grant SG: Neuroproteomics: understanding the molecular organization and complexity of the brain. Nat Rev Neurosci 2009, 10:635-646.

10. Kang HJ, Kawasawa Yl, Cheng F, Zhu Y, Xu X, Li M, Sousa AM, Pletikos M, Meyer KA, Sedmak G, Guennel T, Shin Y, Johnson MB, Krsnik Z, Mayer S, Fertuzinhos S, Umlauf S, Lisgo SN, Vortmeyer A, Weinberger DR, Mane S, Hyde TM, Huttner A, Reimers M, Kleinman JE, Sestan N: Spatio-temporal transcriptome of the human brain. Nature 2011, 478:483-489.

11. Hawrylycz MJ, Lein ES, Guillozet-Bongaarts AL, Shen EH, Ng L, Miller JA, van de Lagemaat LN, Smith KA, Ebbert A, Riley ZL, Abajian C, Beckmann CF, Bernard A, Bertagnolli D, Boe AF, Cartagena PM, Chakravarty MM, Chapin M, Chong J, Dalley RA, Daly BD, Dang C, Datta S, Dee N, Dolbeare TA, Faber V, Feng D, Fowler DR, Goldy J, Gregor BW, et al: An anatomically comprehensive atlas of the adult human brain transcriptome. Nature 2012, 489:391-399.

12. Cooper-Knock J, Kirby J, Ferraiuolo L, Heath PR, Rattray M, Shaw PJ: Gene expression profiling in human neurodegenerative disease. Nat Rev Neurol 2012, 8:518-530.

13. Scholz B, Svensson M, Alm H, Skold K, Falth M, Kultima K, Guigoni C, Doudnikoff E, Li Q, Crossman AR, Bezard E, Andren PE: Striatal proteomic analysis suggests that first L-dopa dose equates to chronic exposure. PLoS One 2008, 3:e1589.

14. Valastro B, Dekundy A, Krogh M, Lundblad M, James P, Danysz W, Quack G, Cenci MA: Proteomic analysis of striatal proteins in the rat model of L-DOPA-induced dyskinesia. J Neurochem 2007, 102:1395-1409.

15. Kultima K, Scholz B, Alm H, Skold K, Svensson M, Crossman AR, Bezard E, Andren $\mathrm{PE}$, Lonnstedt I: Normalization and expression changes in predefined sets of proteins using 2D gel electrophoresis: a proteomic study of L-DOPA induced dyskinesia in an animal model of Parkinson's disease using DIGE. BMC Bioinformatics 2006, 7:475.

16. Bourdenx M, Nilsson A, Wadensten $H$, Falth M, Li Q, Crossman AR, Andren PE, Bezard E: Abnormal structure-specific peptide transmission and processing in a primate model of Parkinson's disease and I-DOPA-induced dyskinesia. Neurobiol Dis 2014, 62:307-312. 
17. Deschepper M, Hoogendoorn B, Brooks S, Dunnett SB, Jones L: Proteomic changes in the brains of Huntington's disease mouse models reflect pathology and implicate mitochondrial changes. Brain Res Bull 2012, 88:210-222.

18. Lessner G, Schmitt O, Haas SJ, Mikkat S, Kreutzer M, Wree A, Glocker MO: Differential proteome of the striatum from hemiparkinsonian rats displays vivid structural remodeling processes. J Proteome Res 2010, 9:4671-4687.

19. Wegrzynowicz M, Holt HK, Friedman DB, Bowman AB: Changes in the striatal proteome of YAC128Q mice exhibit gene-environment interactions between mutant huntingtin and manganese. J Proteome Res 2012, 11:1118-1132.

20. Chin MH, Qian WJ, Wang H, Petyuk VA, Bloom JS, Sforza DM, Lacan G, Liu D, Khan AH, Cantor RM, Bigelow DJ, Melega WP, Camp DG 2nd, Smith RD, Smith DJ: Mitochondrial dysfunction, oxidative stress, and apoptosis revealed by proteomic and transcriptomic analyses of the striata in two mouse models of Parkinson's disease. J Proteome Res 2008, 7:666-677.

21. Zhao X, Li Q, Zhao L, Pu X: Proteome analysis of substantia nigra and striatal tissue in the mouse MPTP model of Parkinson's disease. Proteomics Clin Appl 2007, 1:1559-1569.

22. Liu X, Miller BR, Rebec GV, Clemmer DE: Protein expression in the striatum and cortex regions of the brain for a mouse model of Huntington's disease. J Proteome Res 2007, 6:3134-3142.

23. Patel S, Sinha A, Singh MP: Identification of differentially expressed proteins in striatum of maneb-and paraquat-induced Parkinson's disease phenotype in mouse. Neurotoxicol Teratol 2007, 29:578-585.

24. Skold K, Svensson M, Nilsson A, Zhang X, Nydahl K, Caprioli RM, Svenningsson P, Andren PE: Decreased striatal levels of PEP-19 following MPTP lesion in the mouse. J Proteome Res 2006, 5:262-269.

25. Pierson J, Svenningsson P, Caprioli RM, Andren PE: Increased levels of ubiquitin in the 6-OHDA-lesioned striatum of rats. J Proteome Res 2005, 4:223-226.

26. Basso M, Giraudo S, Corpillo D, Bergamasco B, Lopiano L, Fasano M: Proteome analysis of human substantia nigra in Parkinson's disease. Proteomics 2004, 4:3943-3952.

27. Kitsou E, Pan S, Zhang J, Shi M, Zabeti A, Dickson DW, Albin R, Gearing M, Kashima DT, Wang Y, Beyer RP, Zhou Y, Pan C, Caudle WM: Identification of proteins in human substantia nigra. Proteomics Clin Appl 2008, 2:776-782.

28. Werner CJ, Heyny-von Haussen R, Mall G, Wolf S: Proteome analysis of human substantia nigra in Parkinson's disease. Proc Natl Acad Sci U S A 2008, 6:8.

29. Guo LT, Friedmann T, King CC: Partial characterization of the proteome of the mouse striatum. Proteomics 2007, 7:3867-3869.

30. Bernay B, Gaillard MC, Guryca V, Emadali A, Kuhn L, Bertrand A, Detraz I, Carcenac C, Savasta M, Brouillet E, Garin J, Elalouf JM: Discovering new bioactive neuropeptides in the striatum secretome using in vivo microdialysis and versatile proteomics. Mol Cell Proteomics 2009, 8:946-958.

31. Becker KG, Barnes KC, Bright TJ, Wang SA: The genetic association database. Nat Genet 2004, 36:431-432.

32. Pan S, Shi M, Jin J, Albin RL, Lieberman A, Gearing M, Lin B, Pan C, Yan X, Kashima DT, Zhang J: Proteomics identification of proteins in human cortex using multidimensional separations and MALDI tandem mass spectrometer. Mol Cell Proteomics 2007, 6:1818-1823.

33. Schutzer SE, Liu T, Natelson BH, Angel TE, Schepmoes AA, Purvine SO, Hixson KK, Lipton MS, Camp DG, Coyle PK, Smith RD, Bergquist J: Establishing the proteome of normal human cerebrospinal fluid. PLoS One 2010, 5:e10980.

34. Franceschini A, Szklarczyk D, Frankild S, Kuhn M, Simonovic M, Roth A, Lin J, Minguez P, Bork P, von Mering C, Jensen LJ: STRING v9.1: protein-protein interaction networks, with increased coverage and integration. Nucleic Acids Res 2013, 41:D808-D815.

35. Fernandez-Irigoyen J, Zelaya MV, Santamaria E: Applying mass spectrometry-based qualitative proteomics to human amygdaloid complex. Front Cell Neurosci 2014, 8:80.

36. Kwon KH, Kim JY, Kim SY, Min HK, Lee HJ, Ji IJ, Kang T, Park GW, An HJ, Lee B, Ravid R, Ferrer I, Chung CK, Paik YK, Hancock WS, Park YM, Yoo JS: Chromosome 11-centric human proteome analysis of human brain hippocampus tissue. J Proteome Res 2013, 12:97-105.

37. Fernandez-Irigoyen J, Corrales FJ, Santamaria E: Proteomic atlas of the human olfactory bulb. J Proteomics 2012, 75:4005-4016.

38. Krishnamurthy D, Levin Y, Harris LW, Umrania Y, Bahn S, Guest PC: Analysis of the human pituitary proteome by data independent label-free liquid chromatography tandem mass spectrometry. Proteomics 2011, $11: 495-500$
39. Martins-de-Souza D, Maccarrone G, Reckow S, Falkai P, Schmitt A, Turck CW: Shotgun mass spectrometry analysis of the human thalamus proteome. J Sep Sci 2009, 32:1231-1236.

40. Licker V, Cote M, Lobrinus JA, Rodrigo N, Kovari E, Hochstrasser DF, Turck N, Sanchez JC, Burkhard PR: Proteomic profiling of the substantia nigra demonstrates CNDP2 overexpression in Parkinson's disease. J Proteomics 2012, 75:4656-4667.

41. Licker V, Turck N, Kovari E, Burkhardt K, Cote M, Surini-Demiri M, Lobrinus JA, Sanchez JC, Burkhard PR: Proteomic analysis of human substantia nigra identifies novel candidates involved in Parkinson's disease pathogenesis. Proteomics 2014, 6:784-794.

42. Jin J, Hulette C, Wang Y, Zhang T, Pan C, Wadhwa R, Zhang J: Proteomic identification of a stress protein, mortalin/mthsp70/GRP75: relevance to Parkinson disease. Mol Cell Proteomics 2006, 5:1193-1204.

43. von Eichborn J, Dunkel M, Gohlke BO, Preissner SC, Hoffmann MF, Bauer JM, Armstrong JD, Schaefer MH, Andrade-Navarro MA, Le Novere N, Croning MD, Grant SG, van Nierop P, Smit AB, Preissner R: SynSysNet: integration of experimental data on synaptic protein-protein interactions with drug-target relations. Nucleic Acids Res 2013, 41:D834-D840.

44. Croning MD, Marshall MC, McLaren P, Armstrong JD, Grant SG: G2Cdb: the genes to cognition database. Nucleic Acids Res 2009, 37:D846-D851.

45. Pirooznia M, Wang T, Avramopoulos D, Valle D, Thomas G, Huganir RL, Goes FS, Potash JB, Zandi PP: SynaptomeDB: an ontology-based knowledgebase for synaptic genes. Bioinformatics 2012, 28:897-899.

46. da Huang W, Sherman BT, Lempicki RA: Systematic and integrative analysis of large gene lists using DAVID bioinformatics resources. Nat Protoc 2009, 4:44-57.

47. Kanehisa M, Goto S: KEGG: kyoto encyclopedia of genes and genomes. Nucleic Acids Res 2000, 28:27-30.

48. Mi H, Muruganujan A, Casagrande JT, Thomas PD: Large-scale gene function analysis with the PANTHER classification system. Nat Protoc 2013, 8:1551-1566.

49. Oldham MC, Konopka G, Iwamoto K, Langfelder P, Kato T, Horvath S, Geschwind DH: Functional organization of the transcriptome in human brain. Nat Neurosci 2008, 11:1271-1282.

50. Cahoy JD, Emery B, Kaushal A, Foo LC, Zamanian JL, Christopherson KS, Xing Y, Lubischer JL, Krieg PA, Krupenko SA, Thompson WJ, Barres BA: A transcriptome database for astrocytes, neurons, and oligodendrocytes: a new resource for understanding brain development and function. J Neurosci 2008, 28:264-278.

51. Hopfgartner G, Varesio E, Tschappat V, Grivet C, Bourgogne E, Leuthold LA: Triple quadrupole linear ion trap mass spectrometer for the analysis of small molecules and macromolecules. J Mass Spectrom 2004, 39:845-855

52. Mann M, Kelleher NL: Precision proteomics: the case for high resolution and high mass accuracy. Proc Natl Acad Sci U S A 2008, 105:18132-18138.

53. Andrews GL, Simons BL, Young JB, Hawkridge AM, Muddiman DC: Performance characteristics of a new hybrid quadrupole time-of-flight tandem mass spectrometer (TripleTOF 5600). Anal Chem 2011, 83:5442-5446.

54. Martins-de-Souza D, Gattaz WF, Schmitt A, Rewerts C, Maccarrone G, Dias-Neto E, Turck CW: Proteome analysis of human dorsolateral prefrontal cortex using shotgun mass spectrometry. J Sep Sci 2008, 31:3122-3126.

55. Pan S, Zhu D, Quinn JF, Peskind ER, Montine TJ, Lin B, Goodlett DR, Taylor G, Eng J, Zhang J: A combined dataset of human cerebrospinal fluid proteins identified by multi-dimensional chromatography and tandem mass spectrometry. Proteomics 2007, 7:469-473.

56. Lehnert $S$, Jesse $S$, Rist W, Steinacker $P$, Soininen $H$, Herukka SK, Tumani $H_{\text {, }}$ Lenter M, Oeckl P, Ferger B, Hengerer B, Otto M: iTRAQ and multiple reaction monitoring as proteomic tools for biomarker search in cerebrospinal fluid of patients with Parkinson's disease dementia. Exp Neurol 2012, 234:499-505.

57. Picotti P, Aebersold R: Selected reaction monitoring-based proteomics: workflows, potential, pitfalls and future directions. Nat Methods 2012, 9:555-566.

58. Zhao Y, Giorgianni F, Desiderio DM, Fang B, Beranova-Giorgianni S: Toward a global analysis of the human pituitary proteome by multiple gel-based technology. Anal Chem 2005, 77:5324-5331.

59. Dumont D, Noben JP, Verhaert P, Stinissen P, Robben J: Gel-free analysis of the human brain proteome: application of liquid chromatography and mass spectrometry on biopsy and autopsy samples. Proteomics 2006, 6:4967-4977.

60. Martins-de-Souza D, Guest PC, Steeb H, Pietsch S, Rahmoune H, Harris LW, Bahn S: Characterizing the proteome of the human dorsolateral prefrontal cortex by shotgun mass spectrometry. Proteomics 2011, 11:2347-2353. 
61. Ishii A, Dutta R, Wark GM, Hwang SI, Han DK, Trapp BD, Pfeiffer SE, Bansal R: Human myelin proteome and comparative analysis with mouse myelin. Proc Natl Acad Sci U S A 2009, 106:14605-14610.

62. Legrain P, Aebersold R, Archakov A, Bairoch A, Bala K, Beretta L, Bergeron J, Borchers CH, Corthals GL, Costello CE, Deutsch EW, Domon B, Hancock W, He F, Hochstrasser D, Marko-Varga G, Salekdeh GH, Sechi S, Snyder M, Srivastava S, Uhlen M, Wu CH, Yamamoto T, Paik YK, Omenn GS: The human proteome project: current state and future direction. Mol Cell Proteomics 2011, 10:M111 009993

63. Insel TR, Landis SC, Collins FS: Research priorities. The NIH BRAIN initiative. Science 2013, 340:687-688.

64. Craft GE, Chen A, Nairn AC: Recent advances in quantitative neuroproteomics. Methods 2013, 61:186-218.

65. Altelaar AF, Munoz J, Heck AJ: Next-generation proteomics: towards an integrative view of proteome dynamics. Nat Rev Genet 2013, 14:35-48.

66. Bell JE, Alafuzoff I, Al-Sarraj S, Arzberger T, Bogdanovic N, Budka H, Dexter DT, Falkai P, Ferrer I, Gelpi E, Gentleman SM, Giaccone G, Huitinga I, Ironside JW, Klioueva N, Kovacs GG, Meyronet D, Palkovits M, Parchi P, Patsouris E, Reynolds R, Riederer P, Roggendorf W, Seilhean D, Schmitt A, Schmitz P, Streichenberger N, Schwalber A, Kretzschmar H: Management of a twentyfirst century brain bank: experience in the BrainNet Europe consortium. Acta Neuropathol 2008, 115:497-507.

67. Tang WH, Shilov IV, Seymour SL: Nonlinear fitting method for determining local false discovery rates from decoy database searches. J Proteome Res 2008, 7:3661-3667.

68. Vizcaino JA, Cote RG, Csordas A, Dianes JA, Fabregat A, Foster JM, Griss J, Alpi E, Birim M, Contell J, O'Kelly G, Schoenegger A, Ovelleiro D, Perez-Riverol Y, Reisinger F, Rios D, Wang R, Hermjakob H: The PRoteomics

IDEntifications (PRIDE) database and associated tools: status in. Nucleic Acids Res 2013, 41:D1063-D1069.

69. Ashburner M, Ball CA, Blake JA, Botstein D, Butler H, Cherry JM, Davis AP, Dolinski K, Dwight SS, Eppig JT, Harris MA, Hill DP, Issel-Tarver L, Kasarskis A, Lewis S, Matese JC, Richardson JE, Ringwald M, Rubin GM, Sherlock G: Gene ontology: tool for the unification of biology. The gene ontology consortium. Nat Genet 2000, 25:25-29.

70. Reimand J, Arak T, Vilo J: g:Profiler-a web server for functional interpretation of gene lists (2011 update). Nucleic Acids Res 2011, 39:W307-W315.

71. Wein SP, Cote RG, Dumousseau M, Reisinger F, Hermjakob H, Vizcaino JA: Improvements in the protein identifier cross-reference service. Nucleic Acids Res 2012, 40:W276-W280.

doi:10.1186/s13041-014-0083-9

Cite this article as: Fernández-lrigoyen et al:: Anatomo-proteomic characterization of human basal ganglia: focus on striatum and globus pallidus. Molecular Brain 2014 7:83.

\section{Submit your next manuscript to BioMed Central and take full advantage of:}

- Convenient online submission

- Thorough peer review

- No space constraints or color figure charges

- Immediate publication on acceptance

- Inclusion in PubMed, CAS, Scopus and Google Scholar

- Research which is freely available for redistribution 